\title{
PERFORMANCE IMPROVEMENT IN VECTOR CONTROLLED INDUCTION MOTOR DRIVE BY COMBINING THE PRINCIPLE OF HYBRID PWM AND ANFIS
}

\author{
N. RAVI SANKAR REDDY*, T. BRAHMANANDA REDDY*, J. AMARNATH**, D. SUBBA RAYUDU* \\ "Department of Electrical and Electronics, Faculty of Electrical and Electronics, \\ G. Pulla Reddy Engineering College, Affiliated to JNTUA, Kurnool-518002, India, e-mail: netapallyravi@gmail.com \\ ***awaharlal Nehru Technical University, Hyderabad, Andhra Pradesh, India
}

\begin{abstract}
The complexity involved in the designing of a conventional PI type speed controller for an induction motor is replaced by fuzzy logic controller, synthesized by adaptive neural fuzzy interference system (ANFIS) method. This paper presents a hybrid pulse width modulation (HPWM) algorithm to reduce the steady state ripple in current. The conventional space vector pulse width modulation (CSVPWM) method with equal division of zero state time is modified. To avoid the complex coordinate transformations, trigonometric calculations and sector identification involved in CSVPWM, the concept of imaginary switching times is utilized. The proposed PWM algorithm is designed based on the notion of stator flux ripple. Modulation index and duty cycle dependent expression for rms value of the stator flux over a sampling interval is calculated. Moreover, the rms flux ripple characteristics are graphically illustrated, from which the proposed hybrid PWM algorithm is developed. To validate the proposed algorithm, simulation studies have been carried out and compared with PI controller based vector control of induction motor.
\end{abstract}

Keywords: adaptive neural fuzzy interference system, Discontinuous PWM, Imaginary switching times, stator flux ripple, vector control

\section{INTRODUCTION}

The industrial drives require high performance speed control. In high performance drive systems the motor speed should closely follow a specified reference trajectory regardless of any load disturbances and any model uncertainties. In order to achieve high performance, many schemes have been proposed for the speed control of induction motor drives, among which the vector control is most effective method [1]. The main criterion in an induction motor drive is the design of a controller for response of torque with good transient and steady state responses. Though, PI controller is able to achieve these but with certain drawbacks. The gains cannot be increased beyond certain limit so as to have an improved response. Moreover, it introduces non linearity into the system making it more complex for analysis and deteriorates the controller performance. With the advent of artificial intelligent techniques, these drawbacks can be mitigated.

The design of the controllers such as fuzzy logic, neural network, neuro-fuzzy controllers, etc. do not need exact mathematical model of the system. Simplicity and less intensive mathematical design requirements are the main features of intelligent controllers. However, a simple fuzzy logic controller (FLC) has a narrow speed operation and needs much more manual adjusting by trial and error if high performance is wanted [2-3]. On the other hand, it is extremely tough to create a serial of training data for artificial neural network (ANN) that can handle all the operating modes [4]. The concept of ANFIS has emerged in recent years, as researchers have tried to combine the advantages of both FLC and ANN.

The main concept of a neuro-fuzzy network is derived from the human learning process, where an initial knowledge of a function is first setup by fuzzy rules and then the degree of function approximation is iteratively improved by the learning capabilities of the neural network. The ANFIS utilizes the transparent, linguistic representation of a fuzzy system with the learning ability of artificial neural networks [5]. In [6] an application of Adaptive Neural Fuzzy Inference System (ANFIS) on Vector Control using space vectors pulse width modulation (SVPWM) has been proposed. SVPWM method offers $15 \%$ best bus utilization and better suited for digital implementation.

In CSVPWM algorithm, the voltage reference vector has been approximated by the time averaging over a subcycle of the two adjacent active states and the two zero states. Moreover, it employs equal division of zero voltage vector times within a sampling interval [7]. To overcome this problem, a simplified SVPWM algorithm has been proposed using the concept of imaginary switching times in [11]. Moreover, SVPWM algorithm gives inferior performance over DPWM algorithm at higher modulation indices and at the same time DPWM methods give inferior performance at lower modulation indices. Hence, to overcome these problems, a simplified HPWM algorithm has been proposed in [12], which combines both SVPWM algorithm and DPWM algorithms and gives superior performance at all modulation indices.

In [13] some switching sequences have been developed based on the imaginary switching times and the expressions for rms stator flux ripple over a subcycle are expressed as a function reference voltage vector, imaginary switching times and sampling time. Moreover, HPWM method has been developed from the rms flux ripple characteristics which compares the flux ripple characteristics and uses a sequence, which gives less distortion and is applied in every sampling interval.

Then, a novel of voltage modulation technique has been proposed using the concept of effective time to reduce the computational burden involved in CSVPWM. Also various discontinuous PWM (DPWM) methods have been proposed by utilizing the freedom of zero state 
division. The DPWM methods give less harmonic distortion at higher modulation indices compared to CSVPWM and less switching losses at all modulation indices [8]. To reduce the current ripple at all modulation indices, a few hybrid PWM algorithms have been developed. In these algorithms, expressions for rms stator flux ripple for each sequence have been derived in [9]. Whereas [10] uses a single expression using the conventional space vector approach, which increases the complexity of the algorithm.

To avoid the requirement of reference voltage vector, sector identification and angle determination, the effective time is determined using the concept of imaginary switching times in [14]. This paper presents the Adaptive Neural Fuzzy Inference Systems (ANFIS) controller and an imaginary switching times based hybrid PWM algorithm for reduced current ripple in vector control induction motor drives.

\section{PROPOSED SWITCHING SEQUENCES}

In the CSVPWM, the voltage reference vector has been approximated by the time averaging over a sampling interval of the two adjacent active voltage vectors and two zero voltage vectors. The switching turn-on times of the two active states and two zero states are utilized to determine the duty cycle information to program the active switching gate signals. In the linear modulation operating region of inverter, the sum of the times the two active states are utilized is less than the duration of the subcycle, in which case the remaining time is occupied by using the two zero states. The time share of each space vector is determined by the following equations.

$$
\begin{aligned}
& T_{1}=\frac{2 \sqrt{3}}{\pi} M_{i}\left(\sin \left(60^{\circ}-\alpha\right)\right) T_{s} \\
& T_{2}=\frac{2 \sqrt{3}}{\pi} M_{i}(\sin \alpha) T_{s} \\
& T_{Z}=T_{s}-T_{1}-T_{2}
\end{aligned}
$$

Where $T_{1}$ is Duration for which state 1 is applied in a sampling period in seconds, $T_{2}$ is Duration for which state 2 is applied in a sampling period in seconds, $T_{Z}$ Total duration for which the zero states 0 and 7 are applied in a sampling period in seconds. In the proposed algorithm, the switching times can be calculated by using the concept of imaginary switching times which uses instantaneous values of the reference voltages of $a, b$ and $c$ phases. This method does not depend on the magnitude of the reference voltage space vector and its relative angle with respect to the reference axis. The imaginary switching time periods proportional to the instantaneous values of the reference phase voltages are defined as [10-14]

$$
\begin{aligned}
T_{a n} & \equiv\left(\frac{T_{s}}{V_{d c}}\right) V_{a n} \\
T_{b n} & \equiv\left(\frac{T_{s}}{V_{d c}}\right) V_{b n} \\
T_{c n} & \equiv\left(\frac{T_{s}}{V_{d c}}\right) V_{c n}
\end{aligned}
$$

Where $T_{s}$ is the sampling time, $V_{d c}$ is dc link voltage. When the instantaneous reference voltages are negative, then the corresponding switching times also become negative. Hence these times are called as imaginary switching times. In every sampling time, the maximum, minimum and medium values of imaginary switching times are calculated as

$T_{\text {Max }}=\operatorname{Max}\left(T_{a n}, T_{b n}, T_{c n}\right)$

$T_{\text {Min }}=\operatorname{Min}\left(T_{a n}, T_{b n}, T_{c n}\right)$

$T_{\text {Mid }}=\operatorname{Mid}\left(T_{a n}, T_{b n}, T_{c n}\right)$

Where Max, Min and Mid are the nominal values used during the sampling interval. The function $\operatorname{Max}\left(T_{a n}, T_{b n}, T_{c n}\right)$ selects the maximum value among $T_{a n}, T_{b n}$ and $T_{c n}$. Similarly $\operatorname{Min}\left(T_{a n}, T_{b n}, T_{c n}\right)$ selects the minimum value and $\operatorname{Mid}\left(T_{a n}, T_{b n}, T_{c n}\right)$ selects the middle value. Finally, the active state times $\mathrm{T}_{1}$ and $\mathrm{T}_{2}$ may be expressed as

$T_{1}=T_{\text {Max }}-T_{\text {Mid }}$ and $T_{2}=T_{\text {Mid }}-T_{\text {Min }}$

The zero voltage vector time can be calculated by using equation (7)

$T_{Z}=T_{s}-T_{1}-T_{2}$

By utilizing the freedom of zero state division, various DPWM methods can be generated. In the proposed method the zero state time will be shared between two zero states as $T_{0}$ for $\mathrm{V}_{0}$ and $T_{7}$ for $V_{7}$ respectively, and can be expressed as

$$
T_{0}=k_{o} T_{z} \text { and } T_{7}=\left(1-k_{o}\right) T_{z}
$$

By substituting the value of $k_{o}$ between 0 and 1 in (8), a number of PWM algorithms can be obtained. The CSVPWM algorithm is obtained by substituting $k_{o}=0.5$. When $k_{o}=0$ any one of the phases is clamped to positive dc bus for 120 degrees over a fundamental interval and then DPWMMAX is obtained. When $k_{o}=1$ any one of the phases is clamped to negative dc bus for 120 degrees over a fundamental interval and then DPWMMIN is obtained. Thus, in the first sector, CSVPWM uses 01277210 sequence, DPWMMAX uses 721-127 sequence and DPWMMIN uses 012-210 sequence. Therefore, in the DPWM methods, the switching loss can be reduced by clamping one of the phases to either positive or negative dc bus at a total of $120^{\circ}$ over a fundamental cycle. Hence, the switching frequency of DPWM algorithms is reduced by $33 \%$ compared with CSVPWM. Hence a switching frequency coefficient $\left(\mathrm{k}_{\mathrm{SW}}\right)$ is introduced as defined in (9).

$\mathrm{k}_{\mathrm{sw}}=\frac{\mathrm{f}_{\text {swCSVPWM }}}{\mathrm{f}_{\mathrm{swDPWM}}}$ 


\section{ANALYSIS OF FLUX RIPPLE IN A SAMPLING} INTERVAL

In order to generate the required fundamental voltage sample, the states of the inverter are switched in an average sense at appropriate instants and not in an instantaneously. The difference between applied voltage vector and reference voltage vector is the ripple voltage vector, which depends on space and modulation index.

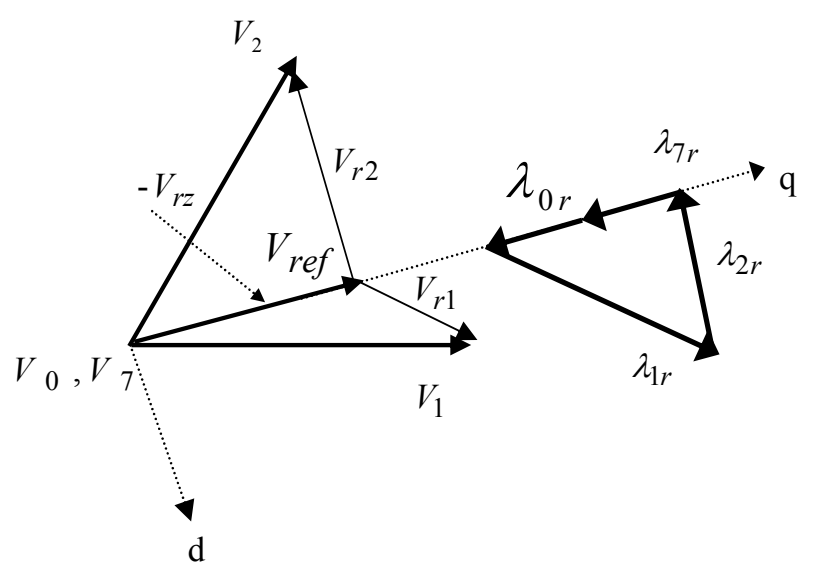

Fig. 1 Voltage ripple vectors and trajectory of the stator flux ripple

Fig. 1 shows the ripple voltage vectors and trajectory of the stator flux ripple. Over a sampling interval, the mean square stator flux ripple can be calculated as

$$
\begin{aligned}
\lambda^{2}{ }_{\text {(rms) }}= & \frac{1}{3}\left\{\lambda_{q 0}^{2} \frac{T_{0}}{T_{s}}+\left[\lambda_{q 0}^{2}+\left(\lambda_{q 0}+\lambda_{q 1}\right)^{2}+\lambda_{q 0}\left(\lambda_{q 0}+\lambda_{q 1}\right)\right] \frac{T_{1}}{T_{s}}\right. \\
& +\left[\left(\lambda_{q 0}+\lambda_{q 1}\right)^{2}+\lambda_{q 7}\left(\lambda_{q 0}+\lambda_{q 1}\right)+\lambda_{q 7}^{2}\right] \frac{T_{2}}{T_{s}} \\
& \left.+\lambda_{q 7}^{2} \frac{T_{7}}{T_{s}}+\lambda_{d}^{2} \frac{\left(T_{1}+T_{2}\right)}{T_{s}}\right\}
\end{aligned}
$$

Where $\lambda_{q 0}, \lambda_{q 1}$ and $\lambda_{q 7}$ are q-axis stator flux ripple vectors during the states 0,1 ,and 7 respectively. By using the above formula, the mean square flux ripple can be easily computed and graphically represented for various PWM methods.

\subsection{Proposed HPWM Algorithm}

The mean square flux ripple characteristics can be obtained from (10) for various PWM algorithms. From Fig. 3, it can be observed that, at higher modulation indices DPWM algorithms give less harmonic distortion compared to CSVPWM algorithm. The RMS stator flux ripple characteristics obtained from equation (10) for various PWM methods are compared for different of modulation index and $k_{s w}$.

From the Fig. 2 - Fig. 3, it can be observed that the SVPWM gives superior performance for $k_{s w}=1$. In order to develop the HPWM algorithm, the value of $k_{s w}$ is taken as $2 / 3$. For $k_{s w}=2 / 3$, the SVPWM gives superior performance at lower modulation indices where as the
DPWM methods give superior performance at higher modulation indices. In order to reduce the current ripple at all modulation indices, a new HPWM is proposed in this paper. The proposed HPWM algorithm consists of a set of PWM algorithms and employs the best algorithm, which gives less ripple for given modulation index.

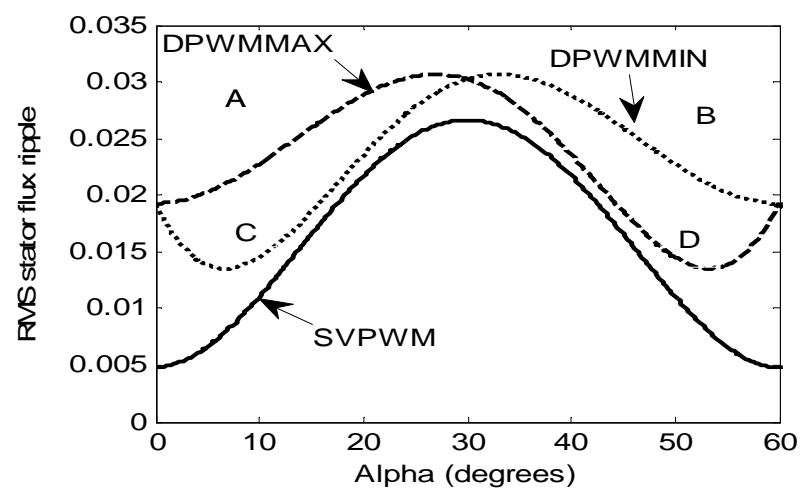

Fig. 2 RMS stator flux ripple of various (PWM methods for $k_{s w}=1$ and $\mathrm{M}_{\mathrm{i}}=0.8 \mathrm{AB}$ : DPWM1, CD: DPWM3, AD: DPWMMAX, DPWM2 and CB: DPWMMIN, DPWM0)

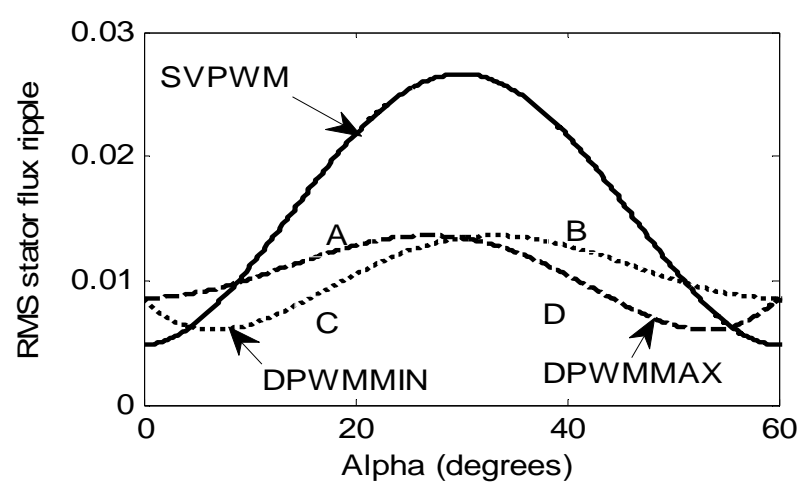

Fig. 3 RMS stator flux ripple of various PWM methods for $k_{s w}=2 / 3$ and $\mathrm{M}_{\mathrm{i}}=0.8(\mathrm{AB}$ : DPWM1, CD: DPWM3, AD: DPWMMAX, DPWM2 and CB: DPWMMIN, DPWM0)

\subsection{HPWM Based Vector Control of Induction motor using ANFIS controller}

The block diagram of HPWM based indirect vector controlled induction motor drive with ANFIS controller is shown in Fig. 4. As shown in Fig. 5, the designed ANFIS which has two inputs i.e., the actual speed $\omega_{r}$ and reference speed $\omega^{*}{ }_{r}$, while the output is the torque, used to generate current $i_{q s}^{*}$.

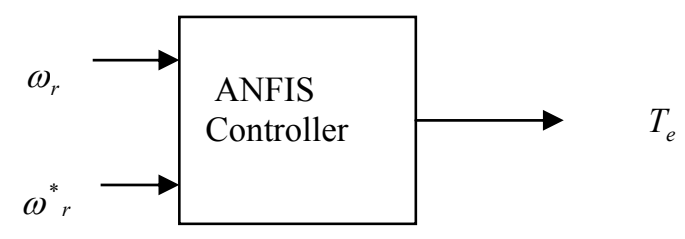

Fig. 5 Logic of ANFIS controller

Adaptive Neuro-Fuzzy Inference Systems (ANFIS) is a class of adaptive networks that are functionally 
equivalent to fuzzy interference system. In the proposed indirect vector control method, the ANFIS neuro-fuzzy system has been used in place of PI controller. First, ANFIS uses the training data set to build the fuzzy system in which, membership functions are adjusted using the backpropagation algorithm, allowing that the system learns with the data that it is modeling.

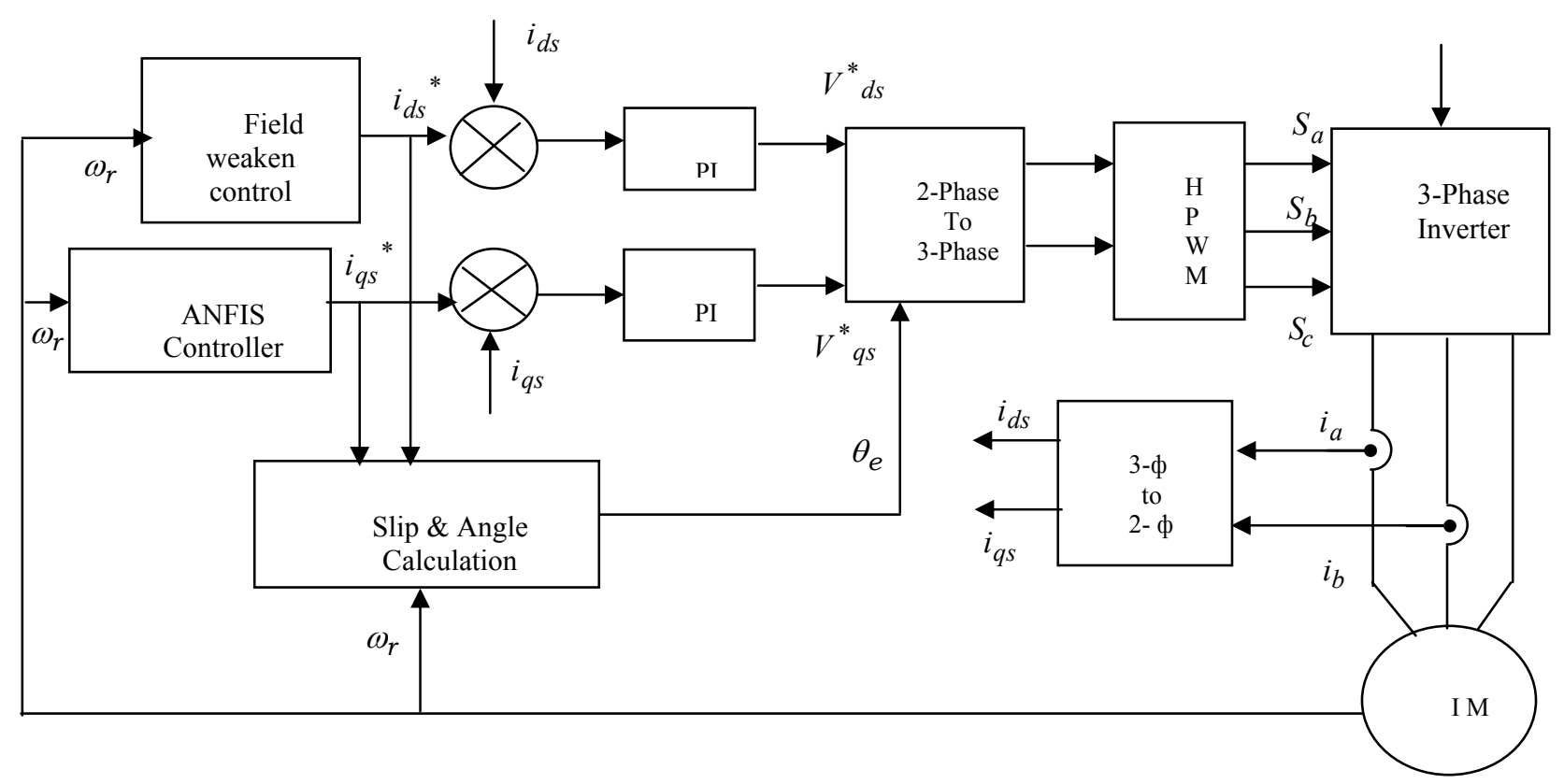

Fig. 4 Block diagram of proposed indirect vector control method

Fig. 6 shows the network structure of the ANFIS that maps the inputs by the membership functions and their associated parameters, and so through the output membership functions and corresponding associated parameters. These will be the synaptic weights and bias, and are associated to the membership functions that are adjusted during the learning process.

In Fig. 6 there are different layers, which are defined as follows:

Layer 1: Every node in this layer contains membership functions.

Layer 2: This layer chooses the minimum value of two input weights.

Layer 3: Every node of these layers calculates the weight, which is normalized.

Layer 4: This layer includes linear functions, which are functions of the input signals.

Layer 5: This layer sums all the incoming signals.

In order to generate fuzzy system sixty five thousand data have been considered. Out of these sixty five thousand data, fifty thousand has been considered as training set data and remaining data has been considered as testing data. The computational work to obtain the parameters and their adjustments is helped by the gradient descendent technique. The number of membership functions considered during the development of ANFIS is 7 and the number of epochs considered is 30. So, in order to develop the ANFIS system, reference speed and actual speed have been considered as inputs and torque has been considered as output. The seven membership functions are
Negative Large (NL), Negative Medium (NM), Negative Small (NS), Zero (Z), Positive Small (PS), Positive Medium (PM) and Positive Large (PL). Table 1 shows the 49 rules $(7 \times 7)$ employed for the implementation of ANFIS network.

Table 1 Rules of proposed ANFIS controller

\begin{tabular}{|c|c|c|c|c|c|c|c|}
\hline $\begin{array}{l}\text { Reference } \\
\text { Speed/ } \\
\text { Actual } \\
\text { Speed } \downarrow\end{array}$ & NL & NM & NS & Z & PS & PM & PL \\
\hline NL & PL & PL & PL & PL & $\mathrm{PM}$ & PS & $Z$ \\
\hline NM & PL & PL & PL & $\mathrm{PM}$ & PS & $\mathrm{Z}$ & NS \\
\hline NS & PS & PM & PM & PS & $Z$ & NS & NM \\
\hline$Z$ & PL & PM & PS & $Z$ & NS & NM & NL \\
\hline PS & $\mathrm{PM}$ & PS & $\mathrm{Z}$ & NS & $\mathrm{NM}$ & NM & $\mathrm{NL}$ \\
\hline $\mathrm{PM}$ & PS & $\mathrm{Z}$ & NS & NM & NL & NL & NL \\
\hline PL & $Z$ & NS & NM & NL & NL & NL & NL \\
\hline
\end{tabular}

The currents $i_{d s}, i_{q s}$ in the vector control are compared with command currents $i_{d s}^{*}$ and $i_{q s}^{*}$ to generate errors. From these errors, the voltage command signals $V_{d s}^{*}$, $V_{q s}^{*}$ can be generated through PI controllers. These voltage commands are then converted into stationary frame and given to HVPWM based inverter, which is shown in Fig. 4. 


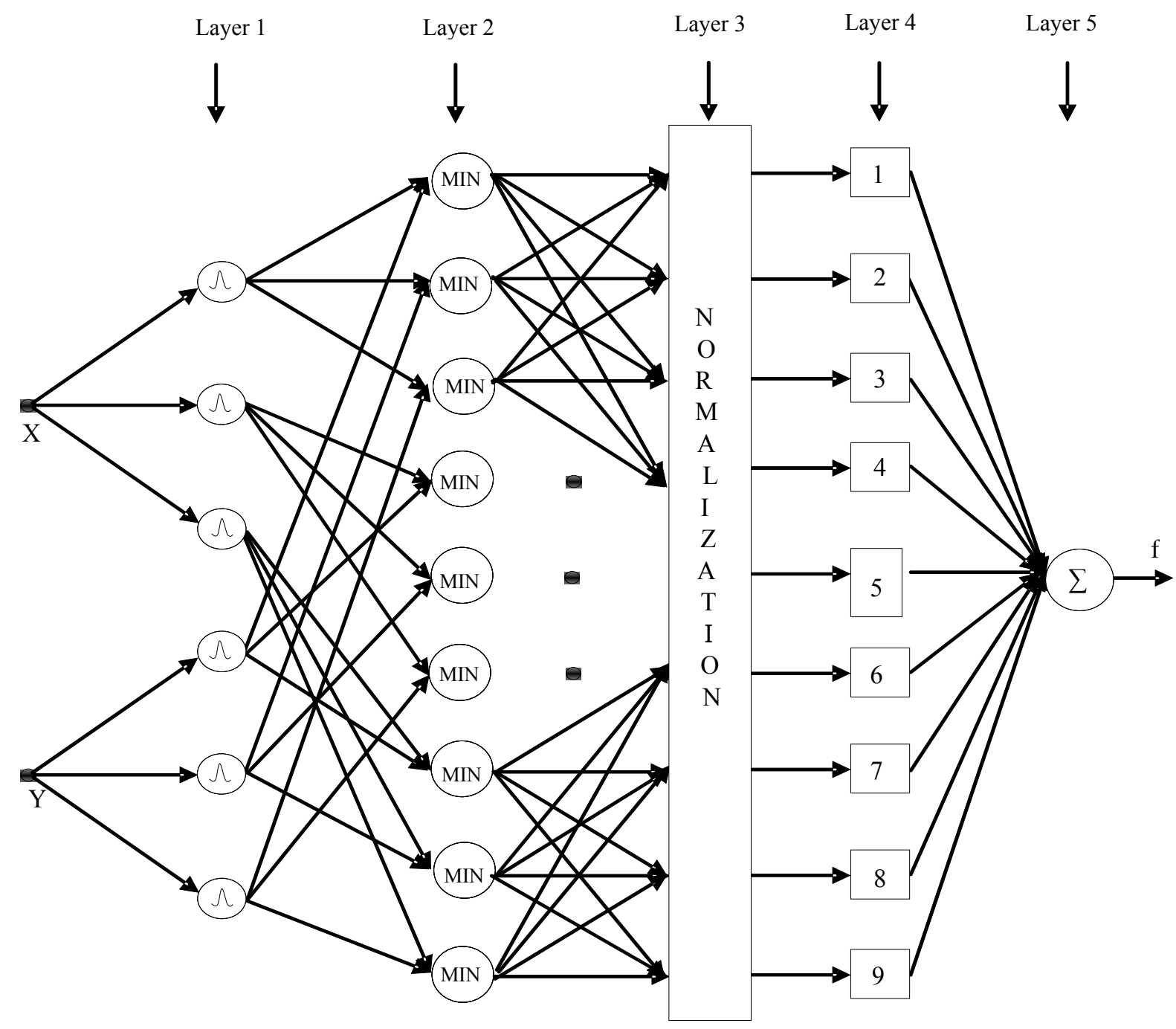

Fig. 6 Network structure of the ANFIS controller
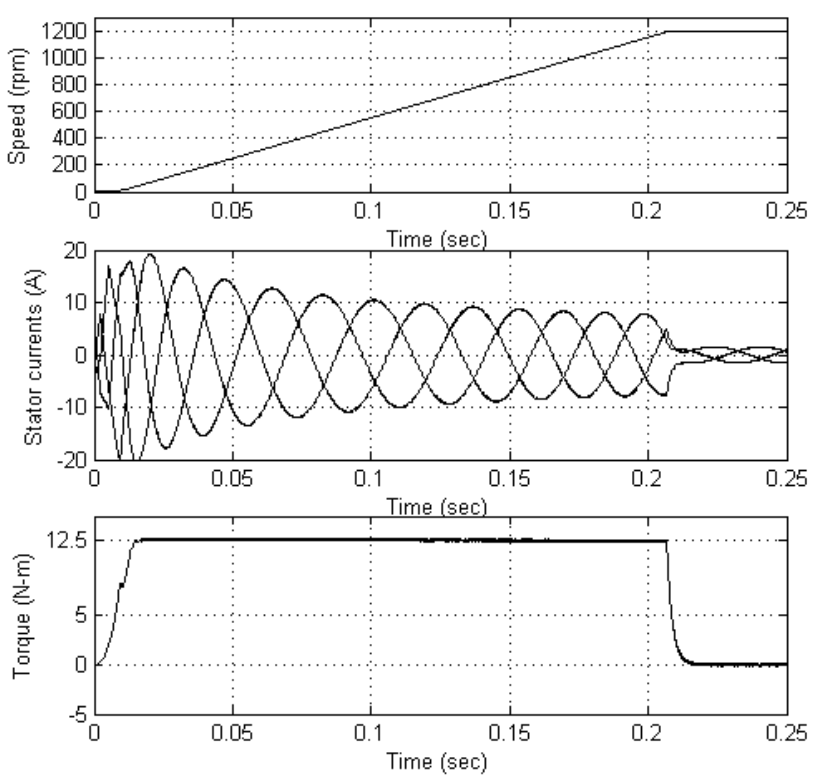

Fig. 7 Starting transients of PI controller HPWM based vector controlled Induction motor drive
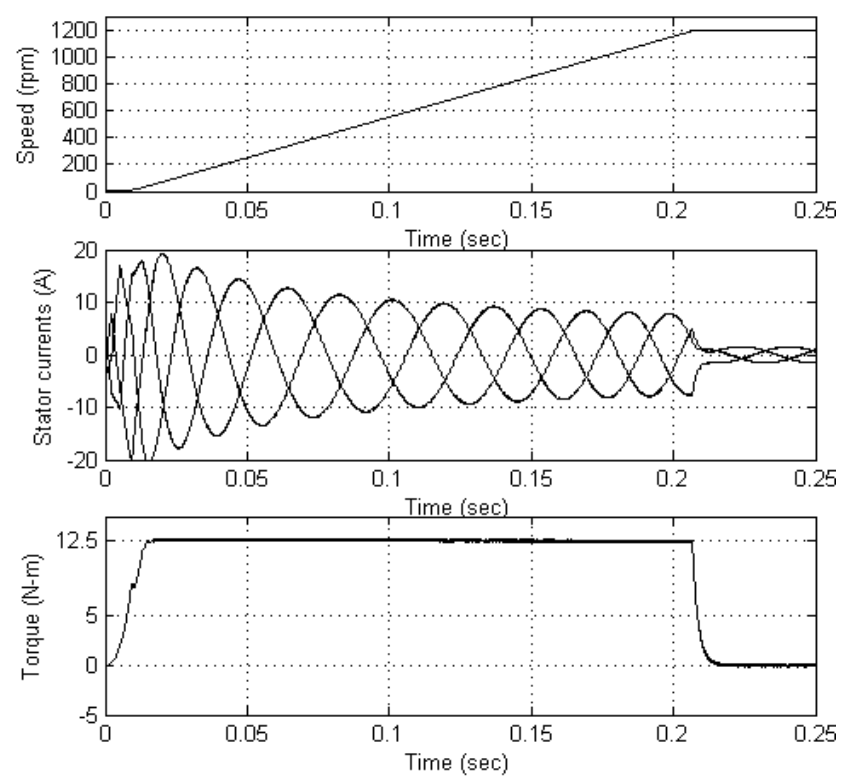

Fig. 8 Starting transients of proposed ANFIS controller HPWM based vector controlled induction motor drive 

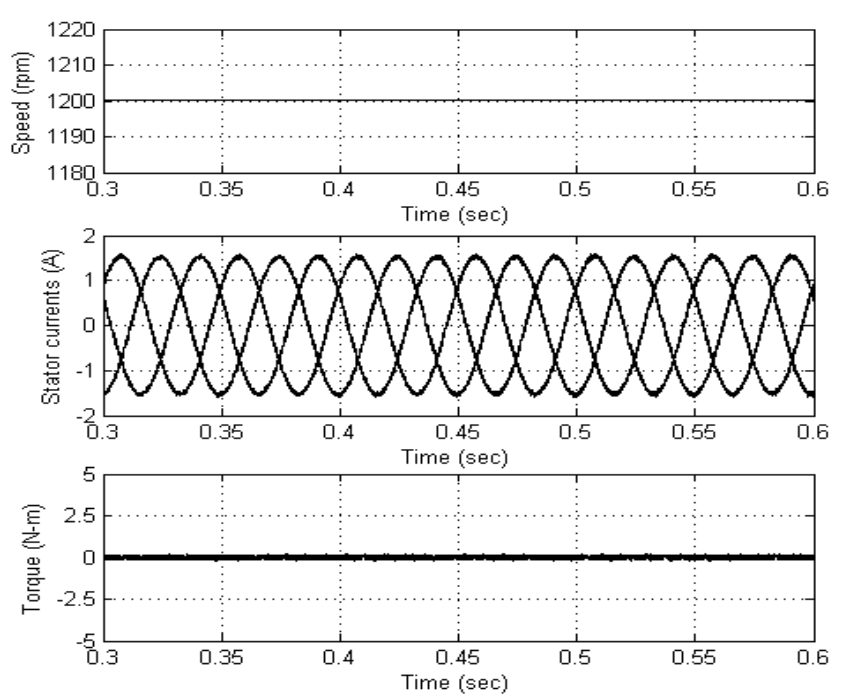

Fig. 9 Steady state plot of PI controller HVPWM based vector controlled induction motor
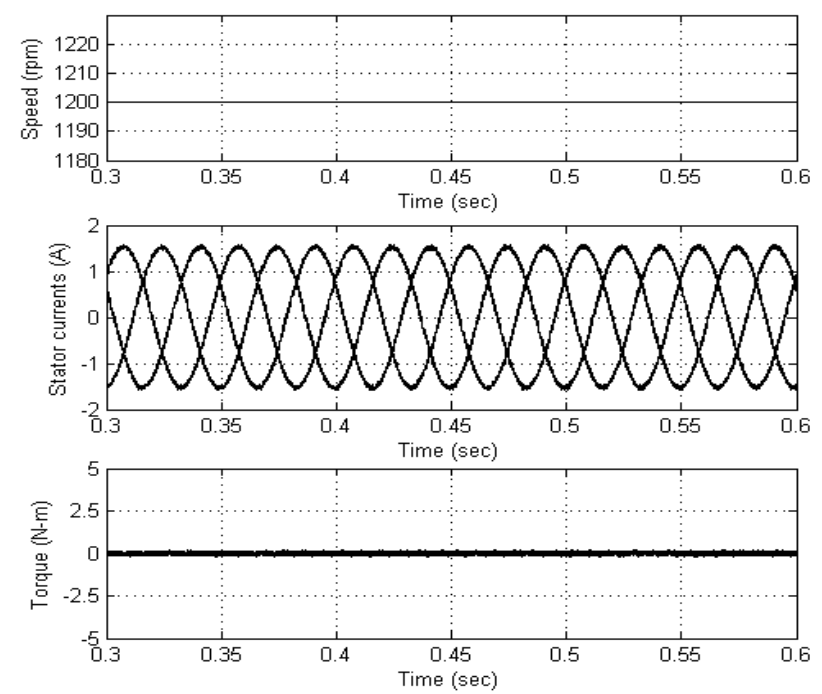

Fig. 10 Steady state of proposed ANFIS controller HPWM based vector controlled induction motor drive
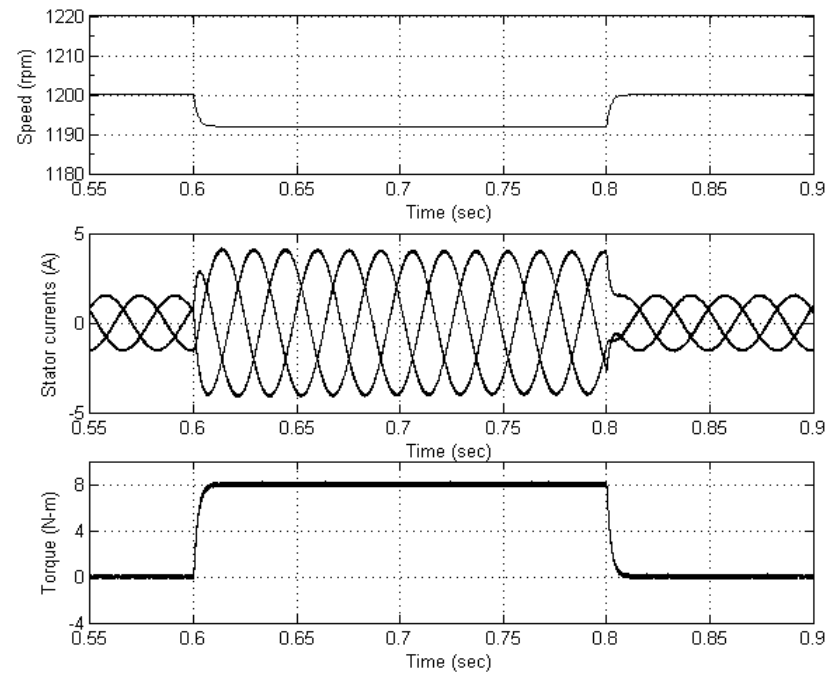

Fig. 11 Transients during step change in load for PI controller HPWM based vector controlled induction motor
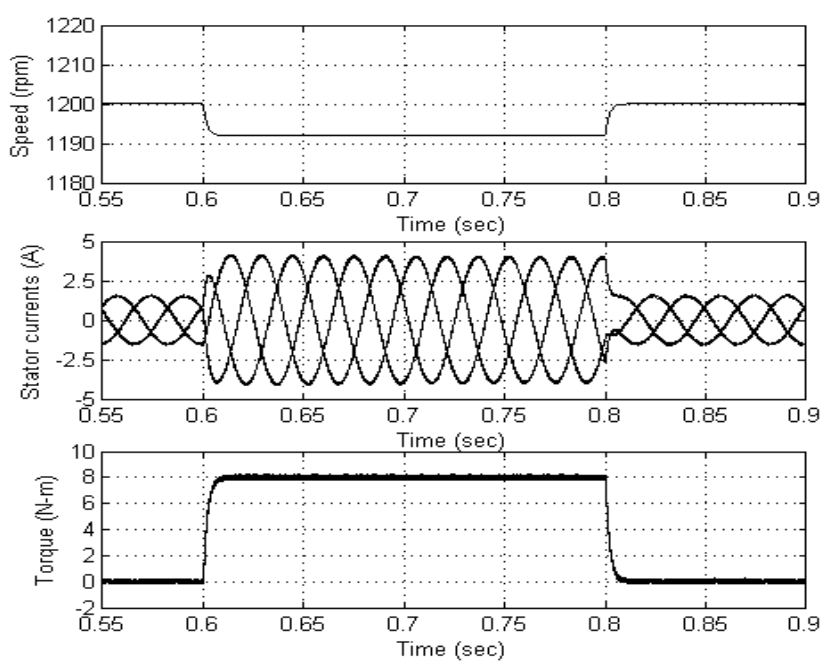

Fig. 12 Transients during step change in load for Proposed ANFIS controller HVPWM based vector controlled induction motor
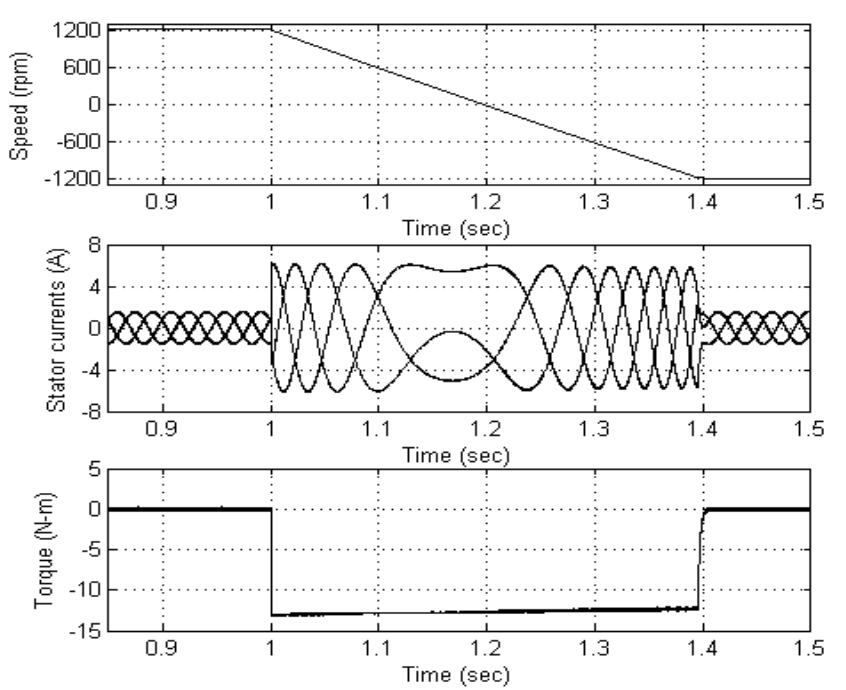

Fig. 13 Transients during speed reversal +1200 r.p.m. to - 200 r.p.m for PI Controller HPWM based vector controlled induction motor
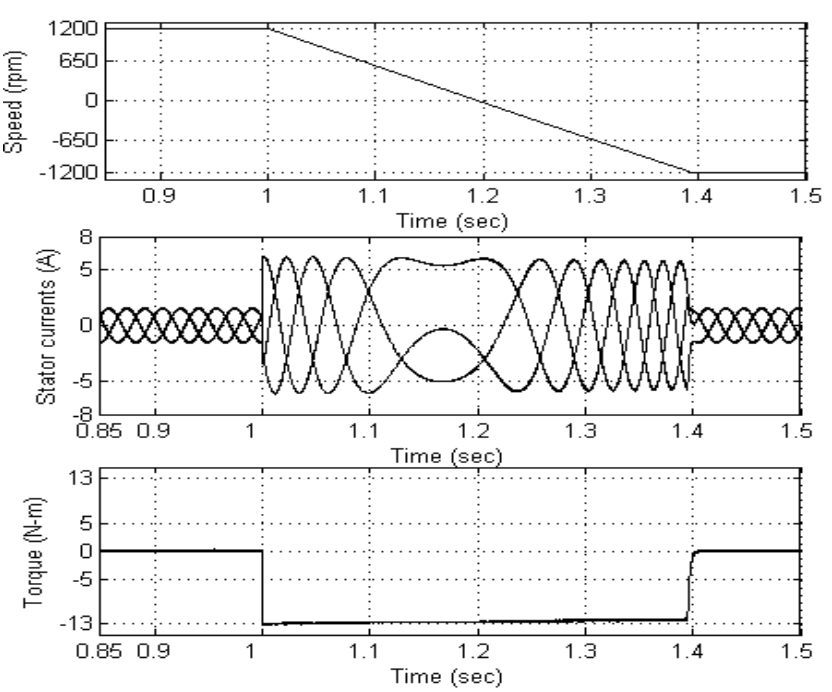

Fig. 14 Transients during speed reversal +1200 r.p.m. to 1200r.p.m for proposed ANFIS Controller HPWM based vector controlled induction motor 

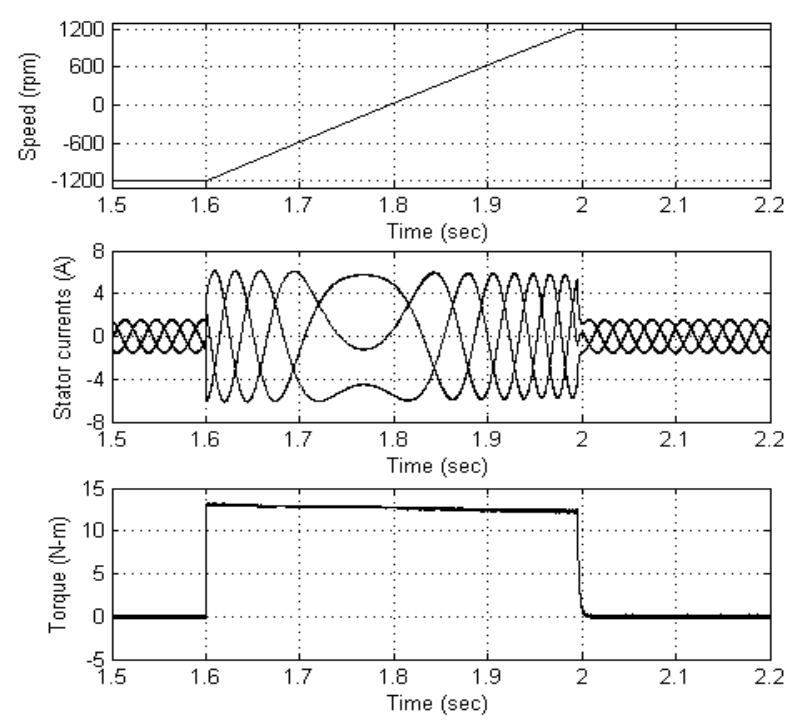

Fig. 15 Transients during speed reversal -1200 r.p.m. to +1200r.p.m for PI Controller HPWM based vector Controlled induction motor
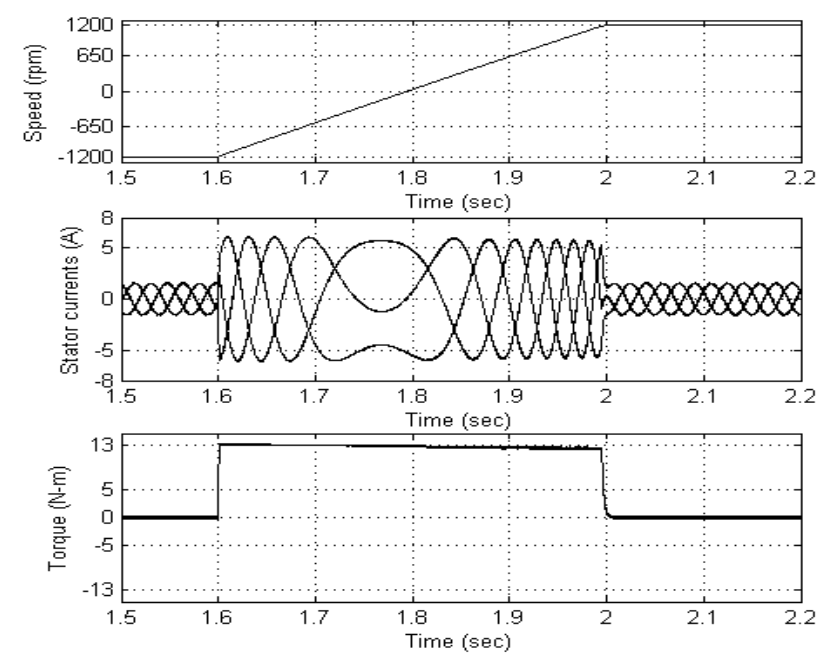

Fig. 16 Transients during speed reversal - 1200 r.p.m. to + 1200r.p.m for proposed ANFIS Controller HPWM based vector controlled induction motor

\section{RESULTS}

To validate the proposed HPWM based vector control of induction motor drive with ANFIS controller, simulation studies have been carried using MATLAB/Simulink. The motor is a squirrel-cage motor with power $1.5 \mathrm{~kW}$, stator resistor $4.1 \Omega$, stator leakage inductance $0.545 \mathrm{mH}$, rotor resistance $2.5 \Omega$, rotor leakage inductance $0.542 \mathrm{mH}$, mutual inductance $0.510 \mathrm{mH}$, inertia $0.04 \mathrm{Kg} \cdot \mathrm{m}^{2}, 2$ pair of poles, dc voltage $780 \mathrm{~V}$.

The simulation results are shown in Fig. 7 - Fig. 16. From the simulation results it can be observed that the ripples in currents and torque are less in proposed ANFIS based HPWM algorithm drive compared to that of PI controller based HPWM algorithm based drive. Also, it can be observed that the proposed HPWM algorithm gives less harmonic distortion.

\section{CONCLUSIONS}

A new controller for Hybrid PWM based vector controlled induction motor drives using ANFIS has been introduced. This method employs backpropagation based neuro-fuzzy structure with five layers. The results obtained by this ANFIS model are more accurate and this approach has solved the problem of the complexity in the design of PI controller. From the simulation results it can be seen that the proposed controller has been implemented successfully. The ripples in current and torque are high for CSVPWM.

Hence to overcome this problem, a new switching sequences has been introduced based on the imaginary switching times which do not require sector and angle information and then the expression for rms ripple over a subcycle are expressed as function of reference voltage vector, imaginary switching times and sampling time based on the notion of stator flux ripple, which gives less distortion and is applied in every sampling interval.

\section{REFERENCES}

[1] BLASCHKE, F.: The principle of field orientation as applied to the new transvector closed loop control system for rotating-field machines, Siemens Review, 1972, pp. 217-220.

[2] UDDIN, M. N. - RADWAN, T. S. - RAHMAN, M. A.: Performances of Fuzzy-Logic-Based Indirect Vector Control for Induction Motor Drive, IEEE Transactions on Industry Applications, Vol. 38, No. 5, Sept./Oct. 2002.

[3] SATEAN TUNYASRIRUT - TIANCHAI SUKSRI - SOMPONG SRILAD: Fuzzy Logic Control for a Speed Control of Induction Motor using Space Vector Pulse Width Modulation, World Academy of Science, Engineering and Technology, 25, 2007.

[4] LIU, G. - HU, Z. - SHEN, Y. - ZHOU, H. - TENG, C.: Estimation of induction motor speed based on artificial neural networks inversion system, IEEE Int. Conf. on Neural Networks \& Signal Processing, China, pp. 43-47, June 8-10, 2008.

[5] GUPTA, R. A. - KUMAR, R. - SURJUSE, R. S.: ANFIS Based Intelligent Control of Vector Controlled Induction Motor Drive, Second International Conference on Emerging Trends in Engineering and Technology, ICETET-09.

[6] Cruz, P. P. - AQUINO, J. M. - ELIZONDO, M. R.: Vector Control using ANFIS Controller with Space Vector Modulation, Universities Power Engineering Conference 2004, 39 International, pp. 545-549, Vol. 1, 2004.

[7] van der BROECK, H. W. - SKUDELNY, H.-C. STANKE, G. V.: Analysis and realization of a pulse width modulator based on voltage space vectors, IEEE Trans. Ind. Applications, Vol. 24, No. 1, Jan./Feb. 1988, pp. 142-150.

[8] DAE-WOONG CHUNG - JOOHN-SHEOK KIM SEUNG-KI SUL: Unified voltage modulation 
technique for real-time three-phase power conversion, IEEE Trans. Industrial Applications, Vol. 34, No. 2, pp. 374-380, Mar./Apr. 1998.

[9] NARAYANAN, G. - RANGANATHAN, V.T. ZHAO, D. - KRISHNAMURTHY, H. AYYANAR, R.: Space vector based hybrid techniques for reduced current ripple, IEEE Trans. Industrial Applications, Vol. 55, No. 4, pp. 16141627, April 2008.

[10] HAVA, A. M. - KERKMAN, R. J. - LIPO, T. A.: Simple analytical and graphical methods for carrierbased PWM-VSI drives, IEEE Trans. Power Electronics, Vol. 14, No. 1, Jan. 1999, pp. 49-61.

[11] RAVISANKAR REDDY, N. - BRAHMANANDA REDDY, T. - AMARNATH, J. - SUBBA RAYUDU, D.: Simplified SVPWM Algorithm for Vector Controlled Induction Motor Drive Using the Concept of Imaginary Switching Times, Intentional Journal of Recent Trends in Engineering, Vol. 2, No. 1, pp. 288-291, Nov. 2009.

[12] RAVISANKAR REDDY, N. - BRAHMANANDA REDDY, T. - AMARNATH, J. - SUBBA RAYUDU, D.: Hybrid PWM Algorithm for Vector Controlled Induction Motor Drive without Angle Estimation for Reduced Current Ripple , ICGSTACSE journal, Vol. 9, Issue 3, Dec. 2009, pp. 4149.

[13] RAVISANKAR REDDY, N. - BRAHMANANDA REDDY, T. - AMARNATH, J. - SUBBA RAYUDU, D.: Family of Space Vector Based Hybrid PWM Methods for Induction Motor Drives without Angle Estimation For Reduced Ripple induction motor drive, International Journal of Distributed Energy Resources, Vol. 6, No. 4, pp. 295-310, July 2010.

[14] BRAHMANANDA REDDY, T. - AMARNATH, J. - SUBBA RAYUDU, D.: Improvement of DTC performance by using hybrid space vector Pulse width modulation algorithm, International Review of Electrical Engineering, Vol. 4, No. 2, pp. 593-600, July - Aug. 2007.

Received May 3, 2012, accepted December 19, 2012

\section{BIOGRAPHIES}

N. Ravi Sankar Reddy was born on 1.06.1975. He obtained a A.M.I.E. in electrical engineering from The Institute of Engineers (IEI), India, Kolkata, He received M. tech from J.N.T. University, Hyderabad in the year 2004.He is presently working as Associate Professor in the Electrical and Electronics Engineering Department at G. Pulla Reddy Engineering college, Kurnool, Andhra Pradesh, India. He is currently pursuing Ph.D at J.N.T. University, Hyderabad.

T. Brahmananda Reddy was born 1979. He graduated from Sri Krishna Devaraya University, Anantapur in the year 2001. He received M.E degree from Osmania University, Hyderabad, India in the year 2003 and Ph.D from J.N.T. University, Hyderabad in the year 2009. He is presently Associate Professor in the Electrical and Electronics Engineering Department, G. Pulla Reddy Engineering College, Kurnool, India. He presented more than 50 research papers in various national and international conferences and journals. His research areas include PWM techniques, DC to AC converters and control of electrical drives.

J. Amarnath graduated from Osmania University in the year 1982, M.E from Andhra University in the year 1984 and Ph.D from J.N.T. University, Hyderabad in the year 2001.He is presently Professor of the Electrical and Electronics Engineering Department, JNTU College of Engineering, Hyderabad and also he is the Chairman, Board of studies in Electrical and Electronics Engineering, JNTU College of Engineering, Hyderabad. He presented more than 120 research papers in various national and international conferences and journals. His research areas include Gas Insulated Substations, High Voltage Engineering, Power Systems and Electrical Drives.

D. Subba Rayudu received B.E degree in Electrical Engineering from S.V. University, Tirupati, India in 1960, M.Sc (Eng) degree from Madras University in 1962 and Ph.D degree from Indian Institute of Technology, Madras, India in $1977 . \mathrm{He}$ is at present working as professor in Department of Electrical and Electronics Engineering at G. Pulla Reddy Engineering College, Kurnool, India. His research interests include Electrical machines, Power Electronics, Analogy electronics and Integrated circuits applications. 